\title{
Exploring the Problems of Teaching Translation Theories and Practice at Saudi Universities: A Case Study of Jazan University in Saudi Arabia
}

\author{
Assistant prof: Amin Ali Al Mubarak ${ }^{1}$ \\ ${ }^{1}$ Department of English language, Jazan University, King of Saudi Arabia \\ Correspondence: Assistant prof: Amin Ali Al Mubarak, Department of English language, Jazan University, King of \\ Saudi Arabia
}

Received: February 28, 2017

Accepted: March 9, 2017

Online Published: March 9, 2017

doi:10.5430/elr.v6n1p87

URL: https://doi.org/10.5430/elr.v6n1p87

\begin{abstract}
The current study deals with the problems of teaching translation from the following perspectives: the significance of translation teaching, the history of translation teaching, teaching materials and teaching methods. The researcher specifically focuses on discovering the problems faced by teachers at the University of Jazan in Saudi Arabia in teaching translation theories and practice. The researcher used a descriptive method in this study to determine the problems faced by teachers in teaching translation. The researcher also distributed a questionnaire to investigate the problems the teachers encountered when teaching translation theories and practice and the questionnaire contained 12 questions. This research did not only reveal the problematic issues encountered but also proposed some practical measures to remedy them. The findings and suggestions would facilitate teachers and relevant authorities to improve the translation teaching methodology in Jazan Universityand the result must not be generalized.
\end{abstract}

Keywords: Translation, Teaching, Teachers

\section{Introduction}

The needs for translation skill are growing rapidly in recent years because of the constant advancement of science, society, and innovation. Moreover, the procedure of translation which comprise by numerous linguistic issues, including sentence structure, connections, and society. The teaching, in general, and teaching translation, in particular, is an exceptionally challenging task since conferring learning and experience to someone else requires total know;edge of the topic, as well as the authority of the correspondence of knowledge. Today, it is believed that translation and Translation Studies, as a discipline, partly share the same grounds with Contrastive Linguistics. Since the second half of the twentieth century, the study of translation is perceived as a distinct knowledge in its particular right. Notably, the developing enthusiasm for the useful investigation of languages had paved the way for further examination of languages from, the pragmatic, semantic, textual and stylistic viewpoints. Similarly, teaching activities in the field of translation studies ought to mirror the current educational advancement.

\section{The Statement of the Problem}

Over the previous decades, there have been remarkable advancements in educational and technical learning methodology. In education, traditional student-teacher instructional relationship has increasingly been supplanted by constructivism, a philosophical viewpoint on how we come to comprehend or know. Constructivism accepts that information is not a previous element to be acclimatized by the learner. Rather, it should be developed by the student $\mathrm{him} /$ herself. Bearing in mind, similar to any other institutions of higher learning, Jazan University provides sufficient lectures, academic staff, a comprehensive curriculum and the outline of the subjects in the course of a study, which subsequently identify clearly the objectives of the course. Despite that, problems do still exist such as the concurrency of language teaching, translation teaching, practices involved in the translation from Arabic into a foreign language along with the complexity of the syllabus and curriculums.

In particular, the content of the current Jazan University's syllabus for teaching translation is more suitable to the Translation Studies instead of the training of translators. To be effective in teaching translation, the teachers should be capable of combining the teaching methodologies they may consider the most useful with those of specifically for teaching translation. Moreover, the problem is intensified because one has to teach translation aids, methods, and doing translation training, both verbal and written, within a limited duration. The teachers should pay particular attention to cultural variations and should inculcate their student's cultural awareness. The selection of educational 
resources should be useful and pedagogically sound, and the teaching approaches should not be aimless. The objective of translation teaching is to provide the learners not only the bilingual capacity but also to support the demeanor and ethics that will permit them to do the finest probable translation work after graduation. Finally, the present study is an attempt to explore the problems of teaching translation at the university level. To conclude, the statement of the problem provides a backdrop for the current study, in its search to provide a broader understanding of the issues involved in the teaching of translation at the university level.

\section{Research Questions}

1. What is the educational inclusion for reinforcing the teaching performances of translation theories' practice at the university level?

2. What are the factors that affect the teaching and motivation of translation theories' practice at the university level?

3. Is the syllabus designed to help the teacher to improve the students' translation competence in translation theories' practice?

\section{The Significance of the Study}

The current study aims to explore the problems of teaching translation theories and practice at the university level in Saudi Arabia. Moreover, this paper responds to the insufficiency of research in this particular area at the university level. Currently, there is limited research that addresses the issues under investigation. It is aimed that the outcomes of this study could assist the administrative authorities to enhance the level of translation skill at the university level.

\section{Review of Literatures}

Teaching translation is a complex task because the one who teaches translation must be an expert in this field, namely, capable of teaching translation theories as a science as well as having the actual practical skills of being a good translator. In other words, they must have a dual capabilities of first, being an expert in teaching the theoretical principles of translation, and simultaneously have the practical skills of an actual translator. In order to identify the actual competencies needed by effective translators, the researcher had investigated and explored the extensive amount of research based on the teaching of translation, and historical development as well as other related issues. The reviewed literature will provide the researcher with the key indicators in deciding the overall approach to the study. Aly (2004) states that the evaluation of the literature discovered that there has been considerable focus on the translation procedure compared to the teaching methods. Teaching is an occupation that can produce something prominent when the correct beliefs and principles of teaching are achieved in the classroom. It is reckoned that the aim of teaching is not to teach learners how to remember truths, or how to know all the correct answers. As Fry et al. (2003) argue that the goal of teaching is primarily to get students to fully comprehend the knowledge being examined. However, teachers may simplify their duties and that of their learners if they take benefit of the suitable implements and approaches. Moreover,(Gabris, 2000) claims that a translation instructor must have familiarity and knowledge in translation and the capability of teaching translation courses at the university level since familiarity and experience of both language are required. Furthermore, (Delisle, 1988) points out that teaching translation is a demanding occupation that could cause fear, induce depression at times, but also rewarding and valuable; thus, it demands trustworthiness and humility. Furthermore (Larsen-Freeman and Anderson, 2013) said that when teaching translation to a learner who is learning a second language at the same time, it is necessary to take into account two essential issues. First, learning how to manage with translation allied problems accurately is not the same as learning the language itself, though they go hand-in-hand. Second, it is indispensable to choose which methodology suits the translation technique used along with the process chosen for translation. Bell (1991) points out that there is a consensus among scholars, translators, teachers of translation teaching and those who are involved with the training of the students to be translators on the main issues that must be addressed in the syllabus for translation courses. The requirements to teach translation include bicultural and bilingual competencies, translation strategies, subject competency and study skills, exposure to conditions and familiarity with the history of translation. Moreover, Bell (1991) also stresses the significance of these requirement and asserts that:

1. Materials should be authentic in terms of tasks and texts. They will be excellent aids for the learners to get a taste of real-world duties and authentic documents.

2. Materials should stimulate discussions between the students. If the students are familiar with differences of opinions translating difficult words in class, it is likely that they are more critical in evaluating their translation when they work as translators. 
3. Materials should permit the learners to concentrate on formal characteristics of the language. Therefore, the students should be skilled enough to decide how they should streamline the same message in unique styles.

4. Materials should support the students to develop their learning skills. The translation practice in class is meant to offer the students with resourceful translation approaches: how to manage the problem of long sentences, how to select words.

5. Materials should support the students to apply their knowledge to work as translators. It is presumed that the students will know how to handle the difficulties of translation after they finish the course.

6. Materials and the teaching policy that are used in teaching translation should aim at preparing the students to be good translators after they complete the course.

Gabris (2000) claims that translation teachers need to have recognized training in language and translation teaching methodologies and should have some accreditations attesting to or documentation to show their capability of translating moreover, (Barcsak, 1996) agrees with Gabris's claims and states that the translation teachers must be skilled in teaching translation. While Gouadec (2000) claims that a new instructor, he or she should expend at least one month working in a translation establishment either as a reviewer or a translator. There are various types of research on education styles, teaching styles and personality types which shows that not each person likes to learn in the same way Watson (1913) shows that not each person likes to learn in the same way being taught in a unique style which can be inconvenient at first, and that can lead to the lack of flexibility. Frank (2005) affirms that for learning to take place, students must be dynamically building the experience in their minds. He also outlines three aspects that are essential to effective learning:

1. Interactive high expectations.

2. Supporting active learning.

3. Offering an assessment and rapid feedback

Brain ( 1990 ) affirms that the indispensable qualities that distinguish excellent teachers are as follows:

1. Familiarity of the subject which means that the teacher must be skillful in his field.

2. Communication which means that the teacher's job is to take advanced knowledge and make it available to the learners to permit students to understand the material.

3. Interest which means that the teacher makes the class stimulating and significant to the students.

4. Respect which means that the respectable teacher has a deep-seated concern and respect for the students in the classroom.

Teachers of translation must be very expert translators themselves, as well as skilled teachers since the most acceptable and capable teachers at a university are practicing professionals in the subject they are teaching Sainz (1994). Furthermore Nogueira (1998) claims that translation teachers must have significant time and passion for their subject. He further argues that trainer should not be working as experts who just happen to teach a limited class here and there. Students require and deserve full-time care. Gerding-Salas (2000) states that there are some organizational steps that needed to be followed in order to teach translation successfully to ensure students' inspiration, efficiency and the excellence of the translated work:

1. The teacher selection of the material to be translated and the texts must be picked perfectly, taking into account the degree of complexity of the texts from the semantic, cultural and stylistic point of view.

2. The learners should read the whole text at least twice with the help of the instructor to be familiar with the subject and to comprehend the source language. The learner and instructor need to bear in mind that meaning is context-determined.

3. The teacher must divide the script into many segments which can help the students to work in groups. This is directly related on the amount of difficulty and the extent of the text that needed to be translated. These parts may be columns, paragraphs, and pages.

4. If the text is familiar to the students, they must do an initial translation. This type of approach can often be done verbally and a recommended note of explanation may be written in the margins.

5. If the text is entirely unfamiliar to the students, they should resort to numerous document sources, which will help the students attain the understanding of the subject under study. 
Hatim and Mason (1990) argue that the teaching of translation within the context requires various sources to accommodate text varieties, teaching, explanation, and discussion. These aspects create different challenges to translators. Apart from that, the preparation of future translators is to be planned around manuscript typologies. Teachers are to start courses with instructional documents, those that addresses what to do in the target-language culture. While Toury (1984) observes that translation teachers had to explain to their students the textual typologies, how to classify and signify the nature of a linguistic hierarchy structure, and about how to transfer the entire meaning of a source language text. The aim of the teacher was to train the students to be the best translators. Toury (1984) does not approve of such viewpoint and chose to train native translators. Native translators are self-educated experts who depend on three connate qualities: inter-linguistic ability, transfer capability, and bilingualism. On the other hand, a translation theory has given great significance to the emotional and cognitive characteristics of the translation procedure. Seleskovitch (1976) claims that when these theoretical problems are applied to his teaching method, students are to be taught not only to render the text but also to translate in a confident manner and this can be done using theoretical studies. Finally, this detailed representation of the literature displays that there are obvious parallels between Translation Studies theory and the present practices of translation teaching and training. Indeed, all teachers have applied their preferred approaches with their learners. The question that remains is why teaching translation is such a problematic job.

\section{Sample of the Study}

In this study, since the size of the population was small, it was crucial to use all the subjects in the population as targets of this study Sekaran (2003). The sample of the survey consisted of 12 teachers who were teaching translation programs during the year 2016/2017 at Jazan University in Saudi Arabia. Since the aims of the study were to explore the difficulties the teacher encountered during the teaching of translation theories and practice. There were obvious rationales behind why this particular group of teachers was chosen as participants. First, the exact criterion for choosing the teachers is their specialization in translation. Second, they have been teaching such courses for many years and are highly experienced.

\section{Research Procedures}

The designed study was the plan employed to conduct the study in a systematic manner as well as aiding in the appropriate organization of the method of data collection. Analyzing the data entails some procedures that are related to each other. The processing of the data began with the analysis of data, and finally classification.

\section{Data Collections}

To collect the data, the questionnaire method was used to explore the problems of teaching translation courses at the university level at Jazan University, Saudi Arabia.The objective was to see the teachers' problems in teaching translation theories. The the researcher designed the questionnaire items and format.

\section{Data Analysis}

The questionnaire was constructed to explore the problems of teaching the practical aspects of translation theories at the university level in Saudi Arabia. Hence, a quantitative method was used for the collection of the data as mentioned earlier, the focus was on Jazan University. In this study, the number of respondents involved were 12 teachers. They were also told that their identities and the responses to the questionnaires will be confidential. In terms of the respondent's demography which has no impact on the level of analysis in this study.

\section{Responses to the Questionnaire}

The researcher has distributed a questionnaire which was used as only tool for the data rallying methods. The survey was carried out to find out about the problems faced teacher when teaching translation theories and practice in Saudi Arabia. The respondents answered the following questions:

10.1 The Most Prominent Issue in Teaching Translation Theories and Practice is the Absence of Textbooks Containing Translated Samples of the Arabic Language into English

The descriptive analysis of data given in Figure 1 show the frequency of the statement: The most prominent issue in teaching translation theories and practice is the absence of textbooks contains translating sample of the Arabic language into English language among the 35 participants. They show that eighty-two percent of the participants strongly agree that the most prominent issue in teaching translation course is the absence of textbooks contains translating sample of the Arabic language into English language is problematic factor while eight percent of the participants agree to the same statement. In addition, six percent of the participants disagree with same statment. Only four percent strongly disagree with same statment. 


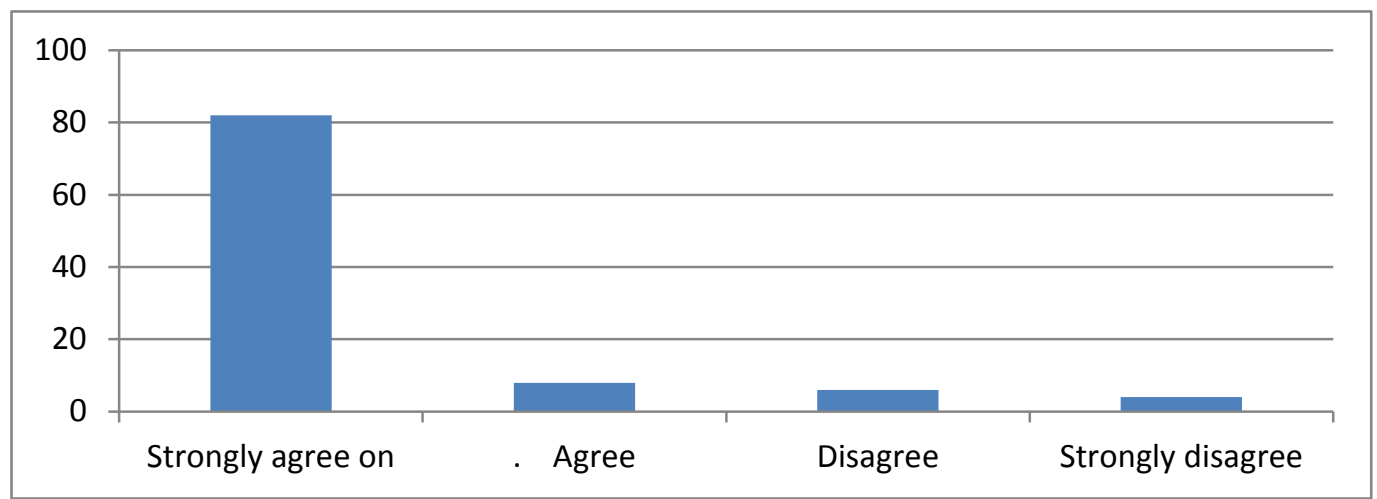

Figure 1. The most prominent issue in teaching translation theories and practice is the absence of textbooks containing translated samples of the Arabic language into English

10.2 Lack of Target Language Cultural Knowledge among Students is One of the Significant Problems for Teaching Translation Theories and Practice

The descriptive analysis of data given in Figure 2 show the frequency of the statement :.lacking of the target language cultural knowledge among the students is one of the significant problems for teaching translation theories and practice among the 35 participants. They show that ninty-five percent of the participants strongly agree that lacking of the target language cultural knowledge among the students is one of the significant problems for teaching translation process while five percent of the participants agree to the same statement.

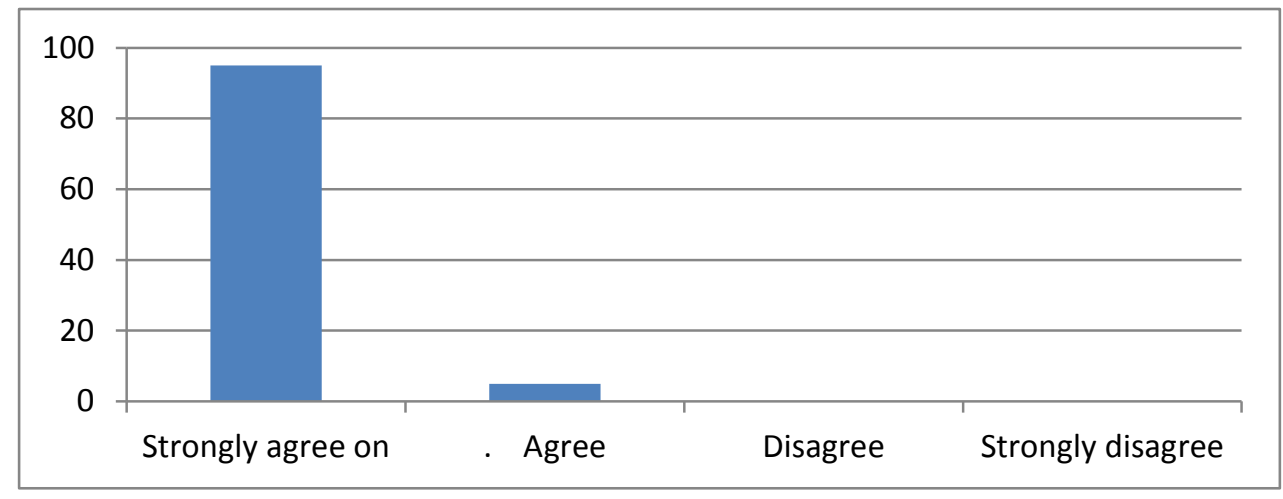

Figure 2. Lack of target language cultural knowledge among students is one of the significant problems for teaching translation theories and practice

10.3 Language Labs and Necessary Equipment for Interpreting Were Lacking; there was Little Practice and Less Theory

The descriptive analysis of data given in Figure 3 show the frequency of the statment : Language labs and necessary equipment for interpreting were lacking ; there was little practice and less theory among the 35 participants. They show that fifty-four percent of the participants strongly agree that the language labs and necessary equipment for interpreting were lacking ; there was little practice and less theory which is problematic factor while twenty-three percent of the participants agree to the same statement. In addition, twelve percent of the participants disagree with same statment. Only eleven percent strongly disagree with same statement 


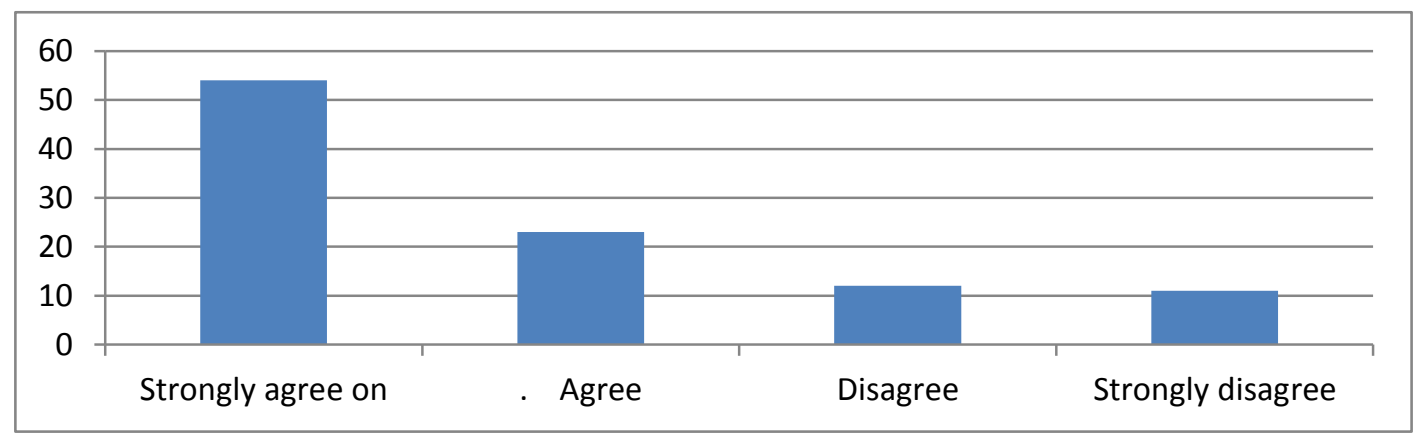

Figure 3. Language labs and necessary equipment for interpreting were lacking ; there was little practice and less theory

10.4 The lack of Motivation for the Students to Improve Their Translation Competence is Challenging Factor in Teaching Process of Translation Theories and Practice

The descriptive analysis of data given in Figure 4 show the frequency of the statement : The lack of motivation for the students to improve their translation competence is challenging factor in teaching process of translation theories and practice among the 35 participants. They show that seventy-seven percent of the participants strongly agree that the lack of motivation for the students to improve their translation competence is challenging factor in teaching process of translation theories and practice while twenty-three percent of the participants agree to the same statement.

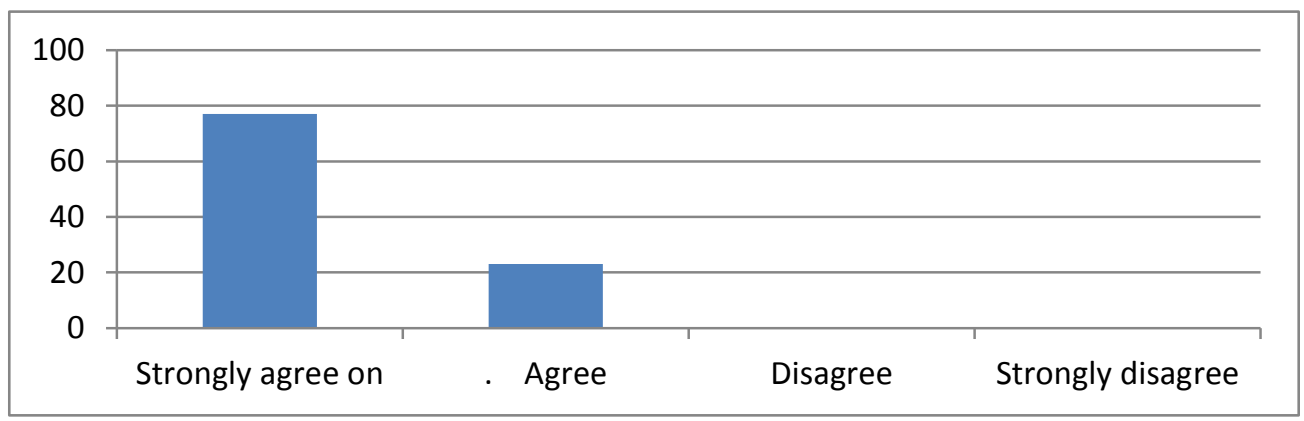

Figure 4. The lack of motivation for the students to improve their translation competence is challenging factor in teaching process of translation theories and practice

10.5 Training and Seminars are Necessary for Translation Teachers because They Need to be Oriented and Guided on how to Handle Students with Different Translation Problems

The descriptive analysis of data given in Figure 5 show the frequency of the statment : Training and seminars are necessary for translation teachers because they need to be oriented and guided on how to handle the students with different translation problems among the 35 participants. They show that sixty-one percent of the participants strongly agree that the training and seminars are necessary for translation teachers because they need to be oriented and guided on how to handle the students with different translation problems while eighteen percent of the participants agree to the same statement. In addition, sixteen percent of the participants disagree with same statment. Only five percent strongly disagree with same statment. 


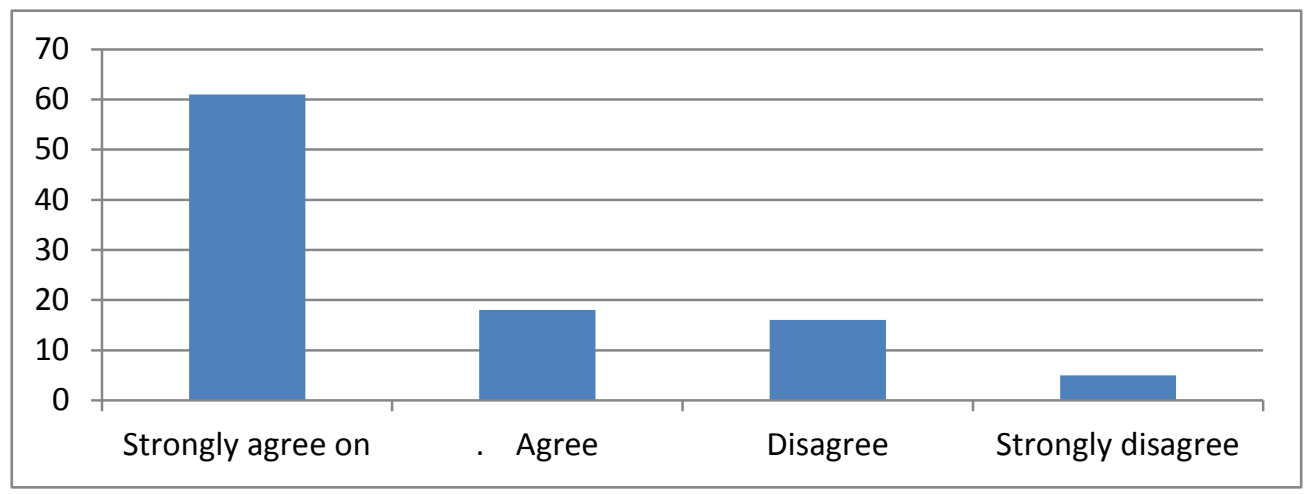

Figure 5. Training and seminars are necessary for translation teachers because they need to be oriented and guided on how to handle students with different translation problems

10.6 More Credit Hours should be Added to Teaching Theories and Practice so that the Problems of Translation in the Classroom can be Uprooted

The descriptive analysis of data given in Figure 6 show the frequency of the statment : More credit hours should be added to teaching theories and practice so that the problems of translation in the classroom can be uprooted among the 35 participants. They show that fourteen percent of the participants strongly agree that more credit hours should be added to teaching theories and practice so that the problems of translation in the classroom can be extirpated while fifty-one percent of the participants agree to the same statement. In addition, eighteen percent of the participants disagree with same statment. Only seven percent strongly disagree with same statment.

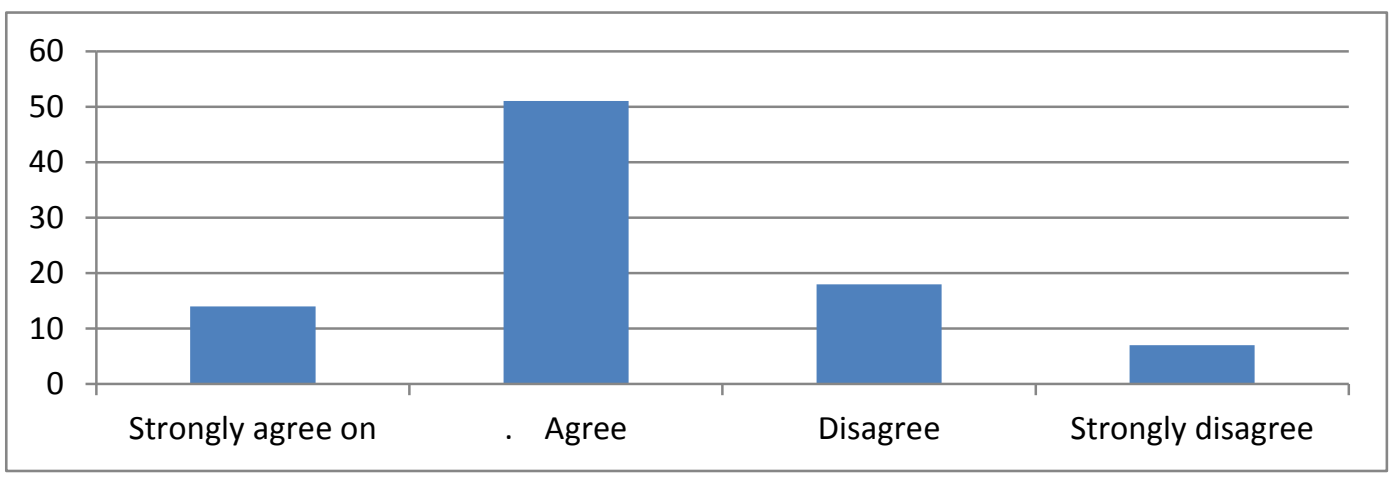

Figure 6. More credit hours should be added to teaching theories and practice so that the problems of translation in the classroom can be uprooted

10.7 The High Number of Learners in each Course is a Barrier for Translation Teachers to Attain Their Teaching Aims in Teaching Translation Theories and Practice

The descriptive analysis of data given in Figure 7 show the frequency of the statment : The high number of learners in each course is a barrier for translation teachers to attain their teaching aims in teaching translation theories and practice among the 35 participants. They show that eighty-three percent of the participants strongly agree that the high number of learners in each course is a barrier for translation teachers to attain their teaching aims in teaching translation while fifteen percent of the participants agree to the same statement. In addition, only two percent of the participants disagree with same statment. 


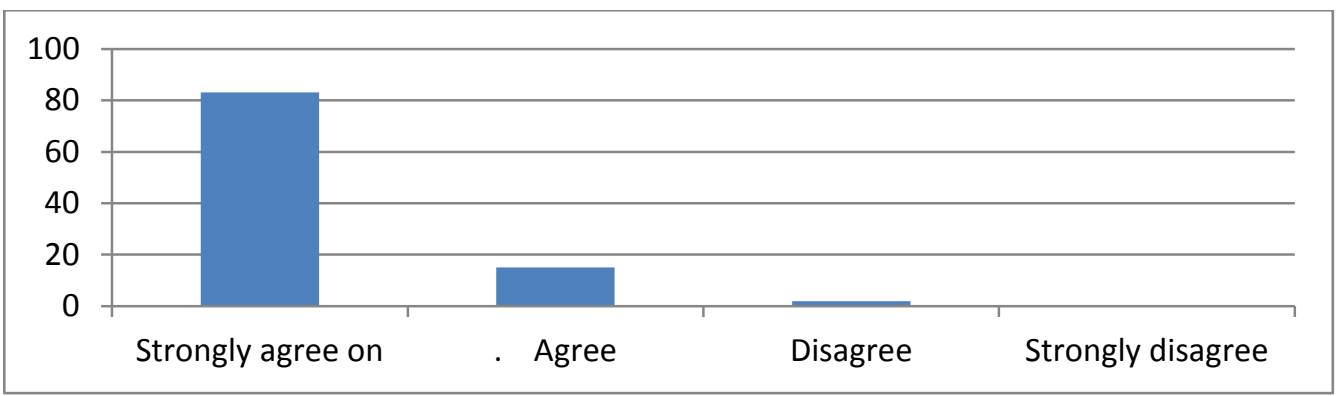

Figure 7. The high number of learners in each course is a barrier for translation teachers to attain their teaching aims in teaching translation theories and practice

10.8 Cooperating Strategy among the Students in the Classroom can Overcome Difficulties in Translation that will Help to improve the Teaching of Translation Theories and Practice

The descriptive analysis of data given in Figure 8 show the frequency of the statment : cooperating strategy among the students in the classroom can overcome difficulties in translation that will help to improve the teaching of translation theories and practice among the 35 participants. They show that twenty-two percent of the participants strongly agree that cooperating strategy among the students in the classroom can overcome difficulties in translation that will help to improve the teaching of translation while forty-one percent of the participants agree to the same statement. In addition, thirty-four percent of the participants disagree with same statment. Only three percent strongly disagree with same statment.

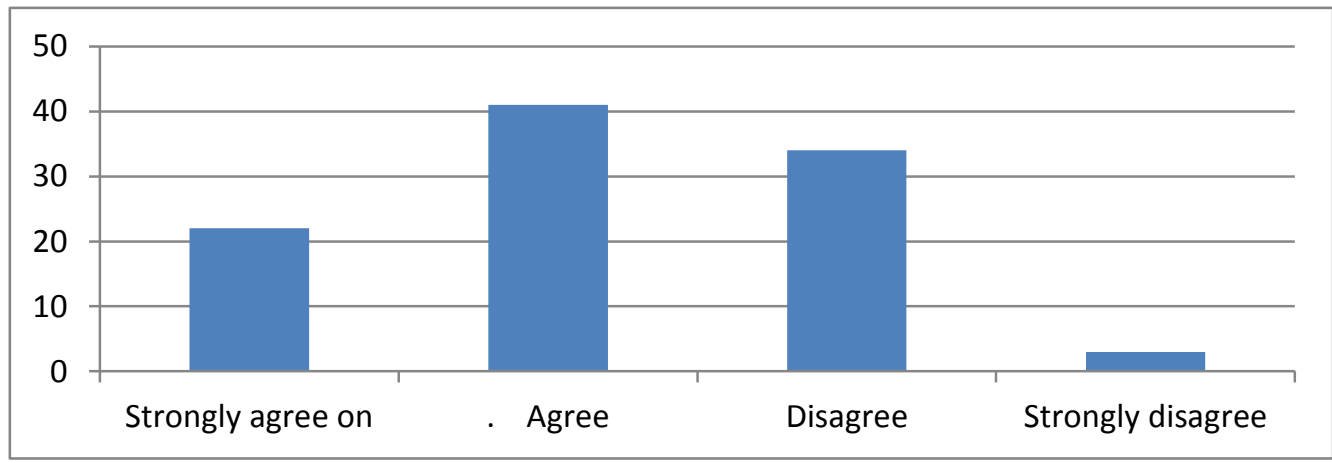

Figure 8. Cooperating strategy among the students in the classroom can overcome difficulties in translation that will help to improve the teaching of translation theories and practice

10.9 The Teacher of Translation Theories and Practice Requires Sophisticated Linguistic Knowledge of both the Source and Target Langauge

The descriptive analysis of data given in Figure 9 show the frequency of the statment : The teacher of translation theories and practice requires a sophisticated and linguistically knowledge of the sources Langauge and target language among the 35 participants. They show that ninty-two percent of the participants strongly agree that the teacher of translation theories and practice requires a sophisticated and linguistically knowledge of the sources Langauge and target language while eight percent of the participants agree to the same statement. 


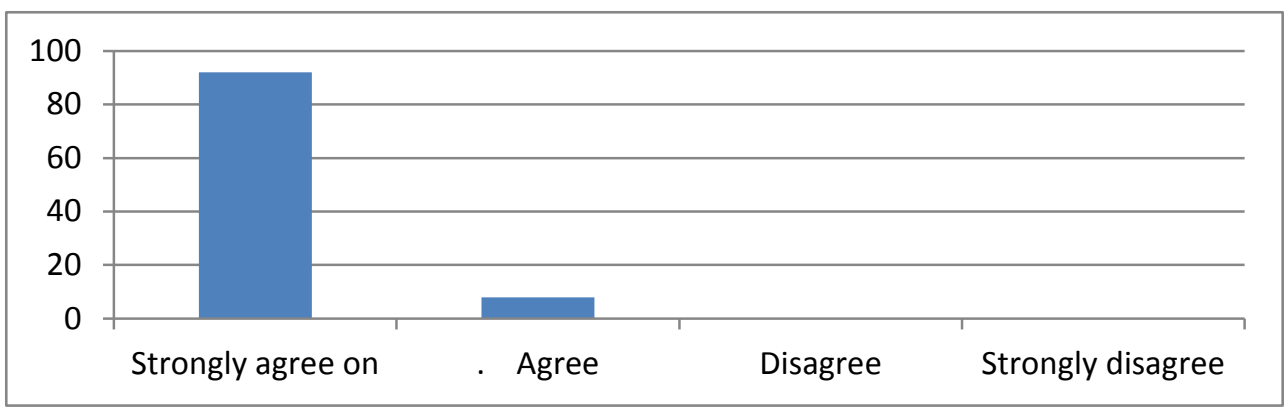

Figure 9. The teacher of translation theories and practice requires sophisticated linguistic knowledge of both the source and target language

10.10 Most of the Translation Courses Textbooks and Handouts, Course Design Rely on Teaching Theories of Translation only

The descriptive analysis of data given in Figure 10 show the frequency of the statment : Most of the translation courses textbooks and handouts, course design rely on teaching theories of translation only among the 35 participants. They show that eighty-three percent of the participants strongly agree that Most of the translation courses textbooks and handouts, course design rely on teaching theories of translation only while nine percent of the participants agree to the same statement. In addition, five percent of the participants disagree with same statment. Only three percent strongly disagree with same statment.

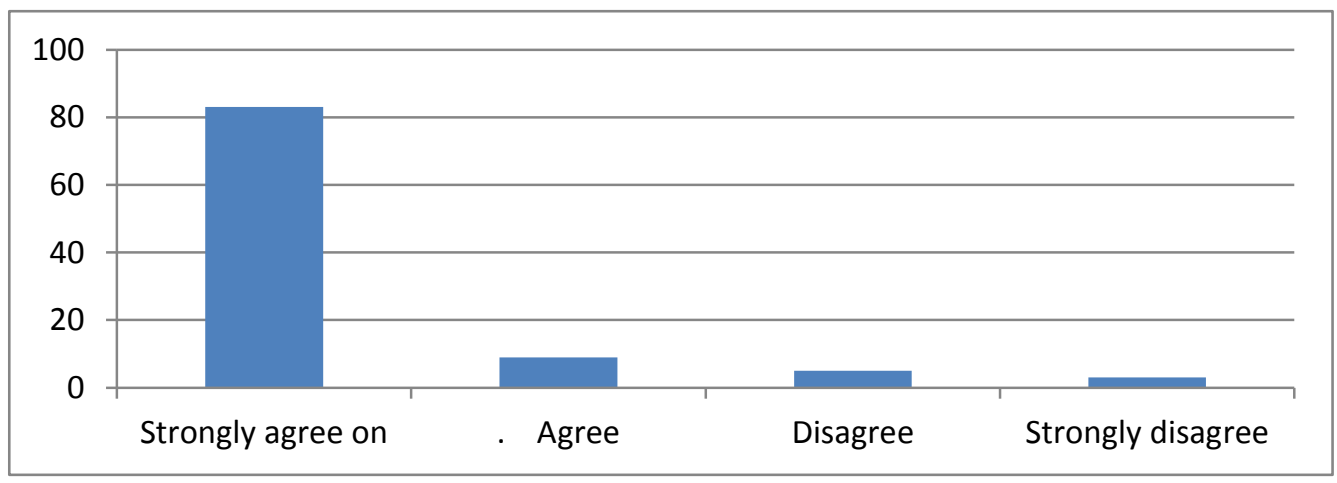

Figure 10. Most of the translation courses textbooks and handouts, course design rely on teaching theories of translation only

10.11 Teachers must be Highly Experienced, and have Extensively Studied of the Theories of Translation, Linguistics, Literature, Aesthetics

The descriptive analysis of data given in Figure 11 show the frequency of the statment : Teachers must be highly experienced, and have extensively studied of the theories of translation, linguistics, literature, aesthetics among the 35 participants. They show that nighty-six percent of the participants strongly agree that teachers must be highly experienced, and have extensively studied of the theories of translation, linguistics, literature, aesthetics only while four percent of the participants agree to the same statement. 


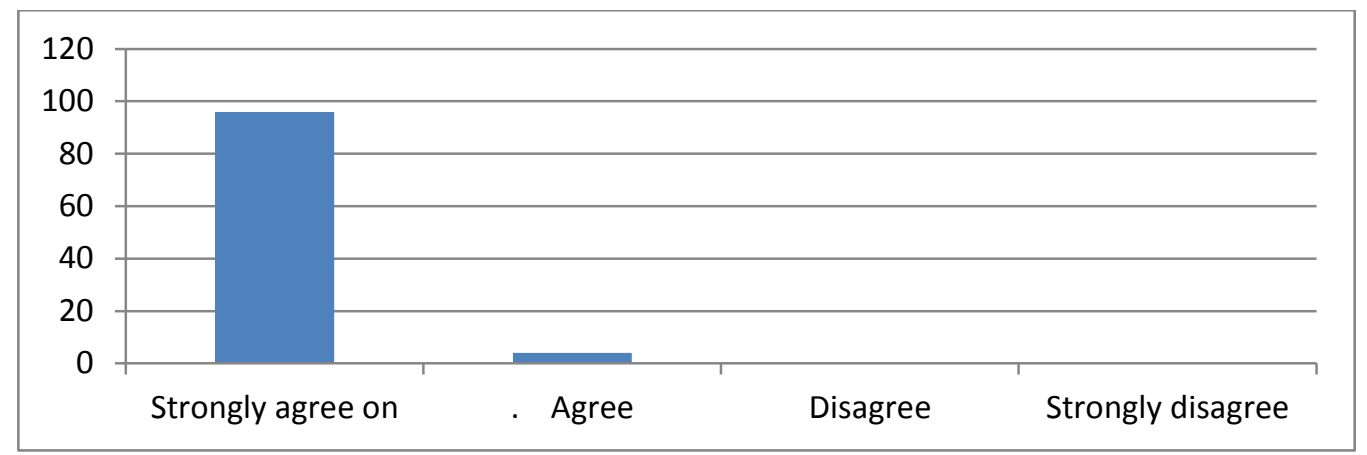

Figure 11. Teachers must be highly experienced, and have extensively studied of the theories of translation, linguistics, literature, aesthetics

10.12 Teacher must be Aware of the Errors Most often Made by Students, and be Talented to Accurately Analyze The Causes of These Errors from the Theories of Linguistics, Culture, Literature

The descriptive analysis of data given in Figure 12 show the frequency of the statement : Teacher must be aware of the errors most often made by students, and be talented to accurately analyze the causes of these errors from the theories of linguistics, culture, literature among the 35 participants. They show that twelve percent of the participants strongly agree that teacher must be aware of the errors most often made by students, and be talented to accurately analyze the causes of these errors from the theories of linguistics, culture, literature while seventy-eight percent of the participants agree to the same statement. In addition, seven percent of the participants disagree with same statement. Only three percent strongly disagree with same statement.

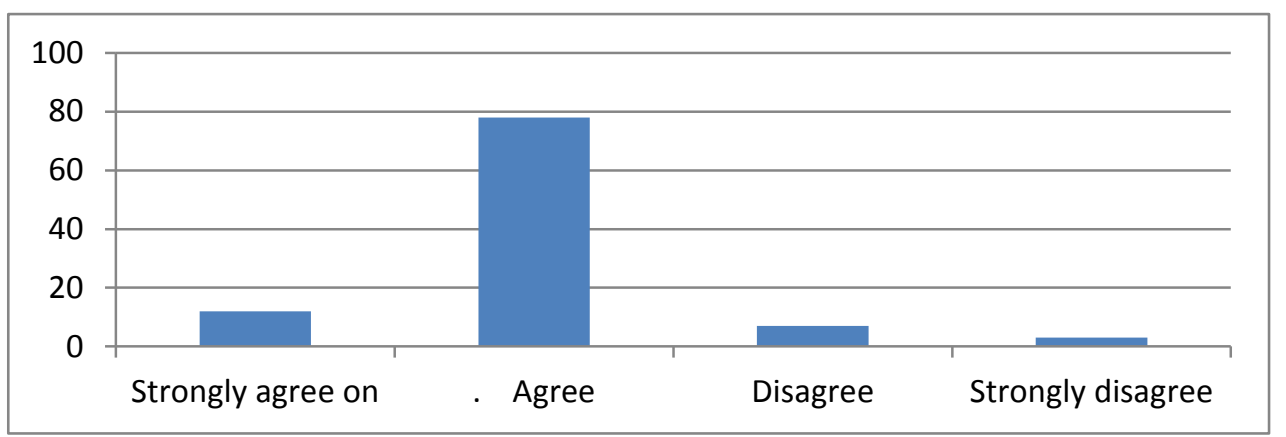

Figure 12. Teacher must be aware of the errors most often made by students, and be talented to accurately analyze the causes of these errors from the theories of linguistics, culture, literature

\section{Discussion and Findings}

The old interpretation of teaching method regards knowledge as being solid. So, students primarily receive knowledge in a mechanical and passive manner and cannot indulge in creativity and enthusiasm. The teaching of translation theories and practice in this out dated approach cannot meet the demands of the professional interpreters and translators. In turn, the students' difficulties in to learn using these approaches lack to the inability of enhancing the learners' translation capabilities. So, it is essential to reproduce and discover new teaching methodology to help translation teaching, increase students' consciousness of independent learning and improve their translation levels.

The primary objective of the quantitative data analysis is to uncover the actual problems faced by teachers when teaching translation in ordinary classrooms. The findings highlighted that there was several issues have impact on the teaching and learning processes. These problems consist of, the English language, instrumentality, integrativeness, knowledge of the target language, and teaching or learning environment. Moreover, the outcomes of this research highlighted and revealed a shortage in the current curricula for the translation programs at the undergraduate level. Any recommended curricular changes in the syllabus must take into consideration the restrictions that undergraduate programs have considers. The connection between theory and practice is likewise critical in a professionally-based university especially during the construction of the programs. One needs to bear in mind that the learners must obtain sound theoretical knowledge before they can enhance their practical skills. But they often failed to have a good grasp 
of the fundamental theories, which they occasionally consider as a waste of time. They must consequently be persuaded of the advantages of mastering a theory before legitimately practising it as a professional translator Roberts (1988). Nevertheless, there are course modifications that can be made to the current curricula without affecting the overall duration of the program. Moreover, the findings also revealed that the undergraduate syllabus does not include the credits hours for English Culture. The importance of culture in teaching translation cannot be underestimated, argued by Karamanian (2002) who insists that translation is connected to the transposition of the views stated in one language into a proper expression in another language. It entails a process of cultural decoding and the teacher should also take into consideration the duration of the lecture. In other words, there should be a suitable time for translation trainees to do practical training as it is the most significant skill required by students to expand their capabilities in translation. The findings also revealed that the methods of teaching translation involves primarily, the content of educational resources, the teacher illustration of each translation skill by giving a huge number of translation cases. Secondly, the teacher allocates translation exercises to learners. Next, the teacher examine the students' completed tasks carefully and assesses their usage of translation skills. Furthermore, the findings of the study confirmed that the importance of translation can no longer be limited to the practice of professionals, but should rather be viewed as an essential activity. Additionally, the finding of the study revealed that the significant aim of any translation courses must incorporate linguistics as the core in order to raise students' awareness of the compound and diverse nature of translation as a process and activity, which depends on both linguistics and non - linguistics factors. The teachers must subsequently, be very qualified, and have broadly knowledge of the theories of translation, phonetics, writing, style and other related branches of learning. They ought to have the capacity to associate the principles of translation with practice and to apply the theories to actual translation. They should identify the errors frequently made by the students, and have the capacity to precisely investigate the reasons for these mistakes from the theories of semantics, culture, writing and style. Furthermore, the findings about the development of translation teaching rely on the assistance of translation studies. As a result, teachers of translation must give particular attention to research on translation teaching theories and other translation methods. Problems such as the teaching program, textbooks, course design, teaching methods, testing and teacher's training, need to be discussed. At the same time, we should encourage investigation into the current state of translation teaching, and the difficulties faced by teachers and students as well as to identify and resolve these problems. Finally, all the findings validate the fact that the teaching of translation theories and practice alone without a well-designed curriculum to provide translators with the valuable information regarding practical skills of translation is problematic. Additionally, the high number of learners in each course is a challenge for translation teachers to achieve their teaching aims. When faced with these problems, it is difficult to effectively instruct the students to skillfully transfer the source language into the target language. It also hinders the students' exposure to the important role of language in the socio-cultural context as well as the impact of their textual choices in the translation process. Furthermore, most of the translation courses textbooks and handouts, course design rely on teaching theories of translation only which lacks practical exposure.

\section{Conclusion}

Teaching is a very challenging mission since conveying information and experience to another person needs not only skills of the subject matter, but also the knowledge of the communication of acquaintance. Teaching translation in typical classroom, it is, hard job that mortifies teachers puts them in a state of misery at times which in line with Li (2006). The study efficaciously raised the teachers' challenges of teaching translation theories and practice in translating from the source language to target language. Moreover, the study displays the possible problems that cause the teaching process of translation theories and practice which include curriculum, the use of materials, equipment's, course-books, and the classroom environment. The aim of translation teaching to students is to acquire general skills in a foreign language and the mother tongue and even a complete understanding. It prepares learners not only with functional bilingual capability but also to encourage the outlooks that will allow them to do the greatest possible translation work after graduation.Moreover, the findings exposed that the difficulties facing translation teaching of theories and practice combine linguistic, cultural, contextualized intuition untranslatability in the source language, knowledge, skills, training, cultural background, expertise. The level of linguistic capability and relationship between preceding knowledge and new insights of learners are often lightened or promoting translation teaching. Since the twentieth century has been called the age of translation, translators. This study has thrown some light on a topic related teaching problems of translation theories faced by teacher. The aim of this study was to identify the obstacles faced by the by the teacher which been highlighted through a questionnaire. 


\section{References}

Aly, M. a.-S. (2004). Translation Strategies of EFL Student Teachers: A Think Aloud Protocol-Based Case Study. Online Submission.

Barcsak, A. (1996). Teaching Literary Translation-A Student's Point of View. Teaching Translation and Interpreting 3. New Horizons. Papers from the Third Language International Conference, Elsinore, Denmark, 9-11 June 1995, 171-174. https://doi.org/10.1075/btl.16.24bar

Bell, R. T. (1991). Translation and translating: Theory and practice. Taylor \& Francis.

Brain, M. ( 1990 ). On translation and translators. U.K: Oxford: Oxford University Press.

Delisle, J. (1988). Translation: an interpretive approach. Univ of Ottawa Pr.

Frank, C. (2005). Teaching and Learning Theory: Who Needs It? College Quarterly, 8(2), n2.

Fry, H., Ketteridge, S., and Marshall, S. (2003). Understanding student learning. A handbook for teaching and learning in higher education: Enhancing academic practice. 28-26.

Gabris, L. (2000). Teaching Translation and Interpretation. Retrieved May.

Gerding-Salas, C. (2000). Teaching translation. Translation Journal, 4(3), 50-62.

Gouadec, D. (2000). Notes on translator training (replies to a questionnaire). International Symposium on Innovation in Translator and Interpreter Training, 11-19.

Hatim, B., and Mason, I. (1990). Discourse and the Translation. London and New York: Longman.

Karamanian, A. P. (2002). Translation and culture. Translation Journal, 6(1), 2.

Larsen-Freeman, D., and Anderson, M. (2013). Techniques and Principles in Language Teaching 3rd edition. Oxford university press.

Li, D. (2006). Making translation testing more teaching-oriented: A case study of translation testing in China. Meta: Journal des traducteursMeta:/Translators' Journal, 51(1), 72-88. https://doi.org/10.7202/012994ar

Nogueira, D. (1998). The business of translating. Retrieved November. 172006.

Roberts, R. P. (1988). The role and teaching of theory in translator training programmes. Meta: Journal des traducteursMeta:/Translators' Journal, 33(2), 164-173. https://doi.org/10.7202/003960ar

Sainz, M. J. (1994). Awareness and responsibility: Our students as partners. Teaching translation and interpreting. 3.

Sekaran, U. (2003). Research methods for business: A skill approach. New Jersey: John Willey and Sons, Inc.

Seleskovitch, D. (1976). Interpretation: A psychological approach to translating. Translation: Applications and research. 92-116.

Toury, G. (1984). The notion of 'native translator'and translation teaching. Die Theorie des Übersetzens und ihr Aufschlusswert für dir Übersetzungs-und Dolmetschdidaktik, Tübingen: Narr, 186-195.

Watson, J. B. (1913). Psychology as the behaviorist views it. Psychological review, $20(2)$, 158. https://doi.org/10.1037/h0074428 